\title{
High Risk of Permafrost Thaw
}

\author{
E.A.G. Schuur ${ }^{1}$, B. Abbott ${ }^{2}$, C.D, Koven ${ }^{3}$, W.J. Riley ${ }^{3}$, Z.M. Subin ${ }^{3}$, et al. \\ ${ }^{1}$ Department of Biology, University of Florida, Gainesville, FL \\ ${ }^{2}$ Institute of Arctic Biology at the University of Alaska, Fairbanks, AK \\ ${ }^{3}$ Lawrence Berkeley National Laboratory, Berkeley, CA
}

(Koven, Riley, and Subin are partially supported by the U.S. Department of Energy and LBNL under Contract No.

DE-AC02-05CH11231.)

Frozen soils in the north are likely to release huge amounts of carbon in a warmer world, say Edward A.G. Schuur and the Vulnerability of Permafrost Carbon Research Coordination Network.

In the Arctic, temperatures are rising fast, and permafrost is thawing. Carbon released to the atmosphere from permafrost soils could accelerate climate change, but the likely magnitude of this effect is still highly uncertain. A collective estimate made by a group of permafrost experts, including myself, is that carbon could be released more quickly than models currently suggest, and at levels that are cause for serious concern.

Recent years have brought reports from the far north of tundra fires ${ }^{1}$, the release of ancient carbon $^{2}$, methane bubbling out of lakes ${ }^{3}$, and gigantic stores of frozen soil carbon ${ }^{4}$. The newest estimate is that some 18.8 million $\mathrm{km}^{2}$ of northern soils hold about 1,700 billion tonnes of organic carbon - the remains of plants and animals that have been accumulating in soil over thousands of years. That's about four times all the carbon ever emitted by human activity in modern times and twice as much as is currently found in the atmosphere.

This soil carbon amount is more than three times higher than previous estimates, largely due to the realization that organic carbon is stored much deeper in frozen soils than was traditionally thought. Inventories typically measure carbon in the top meter of soil. But the physical mixing of freeze-thaw cycles, in combination with sediment deposition over hundreds and thousands of years, has buried permafrost carbon many meters deep.

How much impact carbon emissions from the permafrost zone will have on climate change is determined by the answers to three key questions: how much of this organic carbon is vulnerable to release into the atmosphere; in what form will it be released; and how fast will the release occur? These questions are easily framed but challenging to answer.

As soils defrost, microbes decompose the ancient carbon and release methane and carbon dioxide. Not all carbon is equally vulnerable to release: some soil carbon is easily metabolized and transformed to gases, but more complex molecules are more difficult to break down. The bulk of permafrost carbon is likely to be released slowly over decades after thaw, while a smaller fraction could remain within the soil for centuries or longer. The type of gas released also affects the heat-trapping potential of the emissions. Waterlogged, low-oxygen environments are likely to host microbes that produce methane - a potent greenhouse gas with 25 times the warming potential of carbon dioxide. However, waterlogged environments are also likely to retain higher amounts of carbon within the soil. We don't yet understand how these factors will come together, but how they do determines how thawing permafrost carbon will 
affect future climate.

Our ability to project how much carbon will be released is hampered both by the fact that largescale models are missing potentially important processes, and by a lack of data to inform the models. Most large-scale models simulate future temperature of permafrost soils by assuming that as the air warms, the soils will warm the same amount with a time delay. This warming then increases microbial activity and carbon release. But this is a simplification. Abrupt thaw processes can cause ice wedges to melt and the ground surface to collapse, accelerating the thaw of frozen ground ${ }^{5}$. Evidence for this type of rapid thaw is widespread: you can see it in the form of 'drunken' trees tipping dangerously as a result of ground subsidence, and collapsed hill slopes marked by scars from catastrophic landslides. Model development is slowed by the difficulty in describing these complex, abrupt thaw processes, and by the difficulty of making measurements in these extreme environments. There are only a handful of remote field stations around the world that support this research, while the permafrost zone is extensive- $24 \%$ of the northern hemisphere land area. The field studies that do exist confirm that permafrost thaw is also tightly linked to ground subsidence, and soil moisture as well. This means that modeling carbon emissions from permafrost thaw is much more complex than simple temperature response alone.

While our models are lacking, experts intimately familiar with these landscapes and processes have accumulated knowledge about what they expect to happen, based on both quantitative data and qualitative understanding of these systems. We (the authors of this piece) attempted to quantify this expertise through a survey developed over several years, starting in 2009.

Our survey asked experts what percentage of surface permafrost they thought was likely to thaw, how much carbon would be released, and how much of that would be methane, for three time periods and under four warming scenarios that are part of the new IPCC Fifth Assessment Report. The lowest warming scenario projects $1.5^{\circ} \mathrm{C}$ Arctic warming over the 1985-2004 average by the year 2040, ramping up to $2^{\circ} \mathrm{C}$ warming by 2100 ; the highest warming scenario considers $2.5^{\circ} \mathrm{C}$ Arctic warming by 2040 , and $7.5^{\circ} \mathrm{C}$ by 2100 . In all cases we posited that the temperature would stay steady from 2100 to 2300, in order to assess opinions about the time lag in the response of permafrost carbon to temperature change.

The survey was filled out by a group of 40 international scientists, including myself, who publish on various aspects of permafrost. The results are striking. We collectively hypothesize that the high warming scenario will degrade $9-15 \%$ of the top 3 metres of permafrost by 2040, increasing to $47-61 \%$ by 2100 and $67-79 \%$ by 2300 . Ranges represent $95 \%$ confidence intervals around the mean estimate of the collective group. The estimated carbon release from this degradation is 3063 billion tonnes of carbon over the next three decades, reaching 234-380 billion tonnes by 2100 and 549-865 billion tonnes over the next several centuries. These values, expressed in billions of tons of carbon in $\mathrm{CO}_{2}$ equivalents, combine the effect of carbon released both as $\mathrm{CO}_{2}$ and as $\mathrm{CH}_{4}$.

Our estimate for carbon release by 2100 is 1.7-5.2 times larger than reported by several recent modeling studies using a similar warming scenario ${ }^{6-8}$. Rapid carbon losses projected by our experts, in part, reflect the perceived importance of abrupt thaw processes that are lacking within current models, as well as heightened awareness of these deep carbon pools.

Are these rapid changes in the permafrost soil carbon pool projected by experts plausible? The survey predicts a $7-11 \%$ decrease in the permafrost carbon pool size by 2100 . That's comparable 
to the $7-14 \%$ decrease measured over one or two decades in soil carbon inventories across thousands of sites in the temperate-zone UK as a result of climate change ${ }^{9}$. Also, data scaled from a single permafrost field site points to a potential 5\% loss that could occur over a century with widespread permafrost thaw ${ }^{2}$. These field results are generally supportive of the collective carbon loss projection made by this survey, suggesting these results are indeed plausible.

Across all the warming scenarios, we project that most of the released carbon will be in the form of $\mathrm{CO}_{2}$, with only about $3.5 \%$ in the form of $\mathrm{CH}_{4}$. However, the higher global warming potential of $\mathrm{CH}_{4}$ means that almost half of the effect of future permafrost zone carbon emissions on climate forcing would be from methane emissions from wetlands, lakes, and other oxygenlimited environments. That's roughly consistent with the tens of billions of tonnes of methane thought to have bubbled out of thaw lakes formed in permafrost after the end of the last glacial period $^{10}$.

All this points towards significant carbon releases from permafrost zone soils over policyrelevant scales. It also highlights important lags whereby permafrost degradation and carbon emissions are expected to continue for decades or centuries after a stabilization of global temperatures at new, higher levels. Of course, temperatures might not reach these high levels. Our group's estimates for carbon release under the lowest warming scenario, although still quite sizeable, are about one-third of the emissions predicted under the strongest warming scenario.

$*$

How much permafrost zone carbon is released this century and beyond is critical for determining the appropriate response of humanity to these emissions. Overall, the collective estimate suggests that permafrost thaw will release the same order of magnitude of carbon as deforestation, if current rates of that activity continue. But because the emissions include methane, the overall warming effect would be 2.5 times larger.

Despite the massive amount of carbon in permafrost soils, emissions are unlikely to overshadow fossil fuel burning, which will continue to be the main source of climate forcing. But permafrost carbon release is in some ways more problematic: it occurs in remote places far from human influence, dispersed across the landscape. Trapping carbon emissions at the source as one might do at power plants will not be an option for permafrost. And once the soils thaw, emissions are likely to continue for decades or even centuries.

The scientific community needs increased data collection and more sophisticated modeling to test the hypotheses presented by this survey. Fortunately, awareness of the problem is rising and this is starting to happen. For example, the US Department of Energy has initiated a project called Next-Generation Ecosystem Experiments - Arctic, which aims to improve the representation of complex processes in Earth system models. NASA is pursuing an Arctic-Boreal Vulnerability Experiment, which aims to improve satellite observations of this region. The Vulnerability of Permafrost Carbon Research Coordination Network funded by the NSF, of which we are part, is bringing together people and observations for synthesis and model validation. These are just some of the many new international initiatives aimed at filling these research gaps. In the meantime, this survey outlines the additional risk to society caused by thawing of the frozen north, and underscores the urgent need to reduce fossil fuel use and deforestation emissions now. A co-benefit of this action is keeping more permafrost carbon frozen in the ground longer. 


\section{References}

1 Mack, M. C. et al., Carbon loss from an unprecedented Arctic tundra wildfire. Nature 475 (7357), 489-492 (2011).

2 Schuur, E. A. G. et al., The effect of permafrost thaw on old carbon release and net carbon exchange from tundra. Nature 459 (7246), 556-559 (2009).

3 Walter, K. M. et al., Methane bubbling from Siberian thaw lakes as a positive feedback to climate warming. Nature 443 (7107), 71-75 (2006).

4 Tarnocai, C. et al., Soil organic carbon pools in the northern circumpolar permafrost region. Global Biogeochemical Cycles 23 (in press) (2009).

5 Jorgenson, M. T., Shur, Y. L., and Pullman, E. R., Abrupt increase in permafrost degradation in Arctic Alaska. Geophysical Research Letters 33 (2), - (2006).

6 Schaefer, Kevin, Zhang, Tingjun, Bruhwiler, Lori, and Barrett, Andrew P., Amount and timing of permafrost carbon release in response to climate warming. Tellus B 63 (2), 165-180.

7 C. D. Koven, B. Ringeval, P. Friedlingstein, P. Ciais, P. Cadule, D. Khvorostyanov, G. Krinner, C. Tarnocai. Permafrost carbon-climate feedbacks accelerate global warming. Proceedings of the National Academy of Sciences, 2011; DOI: 10.1073/pnas.1103910108

8 Schneider von Deimling, T., Meinshausen, M., Levermann, A., Huber, V., Frieler, K., Lawrence, D. M., and Brovkin, V.: Estimating the permafrost-carbon feedback on global warming, Biogeosciences Discuss., 8, 4727-4761, doi:10.5194/bgd-8-4727-2011, 2011.

9 Bellamy, P. H. et al., Carbon losses from all soils across England and Wales 1978-2003. Nature 437 (7056), 245-248 (2005).

10 Walter, K. M. et al., Thermokarst lakes as a source of atmospheric CH4 during the last deglaciation. Science 318 (5850), 633-636 (2007). 


\section{DISCLAIMER}

This document was prepared as an account of work sponsored by the United States Government. While this document is believed to contain correct information, neither the United States Government nor any agency thereof, nor The Regents of the University of California, nor any of their employees, makes any warranty, express or implied, or assumes any legal responsibility for the accuracy, completeness, or usefulness of any information, apparatus, product, or process disclosed, or represents that its use would not infringe privately owned rights. Reference herein to any specific commercial product, process, or service by its trade name, trademark, manufacturer, or otherwise, does not necessarily constitute or imply its endorsement, recommendation, or favoring by the United States Government or any agency thereof, or The Regents of the University of California. The views and opinions of authors expressed herein do not necessarily state or reflect those of the United States Government or any agency thereof or The Regents of the University of California.

Ernest Orlando Lawrence Berkeley National Laboratory is an equal opportunity employer. 